\title{
THE CROSS-CORRELATION BETWEEN OUTPUT AND NOMINAL VARIABLES IN NEW KEYNESIAN MODELS CALIBRATED TO BRAZIL AND THE U.S.
}

\author{
Eurilton Araújo *
}

\begin{abstract}
Este artigo investiga se a interação entre formação de hábito e uma regra de Taylor prospectiva consegue reproduzir o padrão de correlação entre produto e variáveis nominais (inflação e taxa de juros) para o Brasil e os Estados Unidos. O estudo emprega um modelo Novo-Keynesiano com rigidez de preço ou de informação. O padrão de correlações vindo dos dados para o Brasil é diferente do padrão para os Estados Unidos. Para ambos os países, os modelos considerados não conseguem reproduzir com um bom grau de precisão os padrões de correlação entre produto e variáveis nominais, embora os modelos de rigidez de preços e de informação impliquem em diferentes mecanismos de propagação dos choques macroeconômicos.
\end{abstract}

Keywords: correlação cruzada, Novo-Keynesiano, variáveis nominais

\begin{abstract}
This paper investigates if the interaction between habit formation and a forward-looking Taylor rule can mimic the observed dynamic correlations between output and nominal variables (inflation and interest rates) in Brazil and in the U.S. I carry out the analysis in a new Keynesian model under sticky price or sticky information. The empirical cross-correlation pattern, obtained from the data, for Brazil is different from the U.S. pattern. For both countries, the models that I considered cannot replicate with a fair amount of accuracy the dynamic correlations between output and nominal variables, though sticky price models and sticky information models imply different propagation mechanisms for macroeconomic shocks.
\end{abstract}

Keywords: Cross-correlation, new Keynesian, nominal variables

JEL classification: E31, E32, E52

\footnotetext{
* Banco Central do Brasil and FUCAPE Business School. Email: eurilton@gmail.com
} 


\section{Introduction}

In a sequence of papers, Fuhrer \& Moore $(1995 a, b)$ focused on the ability of alternative specifications of the New-Keynesian Phillips curve to fit inflation persistence and the co-movement between real output and nominal variables. Indeed, Fuhrer \& Moore (1995b) present dynamic correlations for the U.S. macroeconomic variables to stress the following robust stylized facts: high levels of inflation anticipate low levels of output and high levels of output anticipate high levels of inflation.

Paez-Farrell $(2007,2008)$ shows that the new Keynesian model, though capable of replicating impulse response functions from a vector autoregression (VAR) used to identify macroeconomic shocks, cannot easily match the contemporaneous correlation between output and inflation and the dynamic correlations between output and nominal variables (inflation and interest rates) in the U.S. In fact, the new Keynesian model can replicate some characteristics of the co-movement between output and inflation for an implausible parameterization of the volatility of technology shocks, but at the expenses of the ability to replicate the co-movement between output and interest rates.

Furthermore, María-Dolores \& Vázquez (2008) show that the basic new Keynesian model with habit formation as in Fuhrer (2000) can match the comovement between U.S. output and inflation in the medium-term and longterm horizons, measured by the correlations of VAR forecasting errors of these variables over different forecasting horizons. Den Haan (2000) suggests this VAR-based methodology to measure the co-movement between economic variables by means of dynamic contemporaneous correlations. For each horizon considered, the information set is different, providing a rich picture of how contemporaneous correlations may evolve over time. Thus, this measure can be more informative about the dynamic interaction between economic variables than unconditional correlations.

In a recent paper, Cassou \& Vázquez (2010) extend the methodology of Den Haan (2000) to compute correlations between output and inflation at different horizons, and propose a model to explain the observed patterns. The model features a very high degree of habit persistence, which generates a rich forward-looking structure in demand, introducing additional forwardlooking terms in the traditional IS curve. To a certain extent, this model is capable of replicating the dynamic correlation patterns at different horizons as long as the right balance between the effects of supply and demand shocks obtains through a calibration method that resemble the simulated method of moments.

In this paper, I ask whether variants of the model investigated in MaríaDolores \& Vázquez (2008) can replicate the dynamic correlations between output and nominal variables in Brazil and in the U.S. I carry out the analysis in a new Keynesian model under sticky price or sticky information since the correlation patterns may depend on the interaction between habit persistence and the nature of the price-setting behavior. Therefore, this study extends the work of Paez-Farrell (2008), by focusing on the role of the following features: habit formation, a forward-looking Taylor rule and alternative price-setting schemes. These elements were absent in the variants of the new Keynesian model he investigated.

This paper also complements the work of María-Dolores \& Vázquez (2008) by looking at additional metrics of co-movement, since it addresses the cross- 
correlation between output and the interest rate.

Compared with María-Dolores \& Vázquez (2008) and Cassou \& Vázquez (2010), which considered habit formation and hybrid Phillips curves, I investigate the role of a forward-looking Taylor rule as well as the effect of stickyinformation as introduced by Mankiw \& Reis (2002). In addition, this paper studies two different economies: Brazil, an emerging economy, and the U.S.

In short, this paper therefore differs from previous papers by considering alternative theories for inflation dynamics, by incorporating a forwardlooking Taylor rule with an explicit role for inflation expectations in monetary policy and by explicitly analyzing two distinct economies, Brazil and the U.S.

I summarize the main findings in this paragraph. First, Brazil and the U.S. display somewhat different cross-correlation patterns between output and nominal variables (inflation and the interest rate). Second, the models considered cannot match, with a fair amount of accuracy, the cross-correlation pattern in the data for Brazil and for the U.S. For Brazil, due to the high degree of uncertainty implied by simulated confidence bands, the empirical cross-correlations are within these bands, though the simulated mean crosscorrelations are far from the observed cross-correlations. For the U.S., the models do not improve much upon the traditional new Keynesian specification. In fact, introducing habit formation and a forward-looking Taylor rule did not help much, especially in capturing the dynamic relationship between inflation and the output gap. Further, dynamic responses of output, inflation and the interest rate are somewhat different for the sticky price compared to the sticky information specification, especially the response to supply shocks. This feature may explain the different shapes for the mean simulated crosscorrelations across alternative price-setting specifications.

This paper proceeds as follows. The second section presents observed dynamic correlations between output and nominal variables for Brazil and the U.S. under alternative filtering techniques used to remove the output trend. The third section introduces the variant of the new Keynesian model suggested by María-Dolores \& Vázquez (2008) under alternative price-setting schemes. The fourth section presents the results concerning the role of habit formation and forward-looking Taylor rules in replicating the dynamic correlations between output and nominal variables in models with sticky prices or sticky information. The fifth section discusses impulse response analysis of key macroeconomic variables to demand and supply shocks under the two alternative price-setting shemes. Finally, the sixth section concludes.

\section{Measuring the dynamic correlations between output and nominal variables}

Figures 1 to 4 present the cross-correlation between output and two nominal variables (inflation and the interest rate). I will use these moments to evaluate alternative specifications of the new Keynesian model. Figures 1 to 2 show the correlation patterns in Brazil, while figures 3 to 4 focus on the U.S. I remove the output trend using two alternative filtering techniques, the Hodrick-Prescott filter and the Christiano-Fitzgerald band pass filter. Therefore, following Fuhrer \& Moore (1995b), as well as Cassou \& Vázquez (2010), I report the cross-correlation between the output gap and the nominal variables. 


\subsection{Brazil}

For Brazil, the data come from the IFS database of the IMF. I use quarterly observations on real GDP, consumer price inflation and T-Bill rates, starting at the first quarter of 1995 and ending in the last quarter of 2010. I report the asymptotic two standard error bounds. Since the sample is very short, only 64 observations, just few dynamic correlations, concerning output and lagged interest rate are different from zero. In fact, the bounds are a decreasing function of the sample size and their magnitudes in absolute values are relatively large compared with the observed dynamic correlations. The motivation for choosing such small sample is the necessity to exclude the Brazilian hyperinflationary period with several structural breaks and unstable macroeconomic environment. I therefore focus on a period of stable inflation.

Inspecting figures 1 and 2, no statistically significant pattern emerges. Considering the correlations between lagged inflation and the output gap, as well as the correlations between lagged interest rates and the output gap, they are negative for short lags and a positive pattern emerges for long lags. The correlation pattern concerning inflation and the lagged output gap, though not so clear depending on the filtering techniques, tend to be negative for short lags. Using the Christiano-Fitzgerald filter, the dynamic correlations are negative for short lags and positive for long lags, increasing monotonically. Finally, the dynamic correlations between interest rates and the lagged output gap have negative values for short lags, positive magnitudes for intermediate lags and negative values for long lags.

The contemporaneous correlation between the output gap and inflation and the contemporaneous correlation between the output gap and the interest rate are both negative.
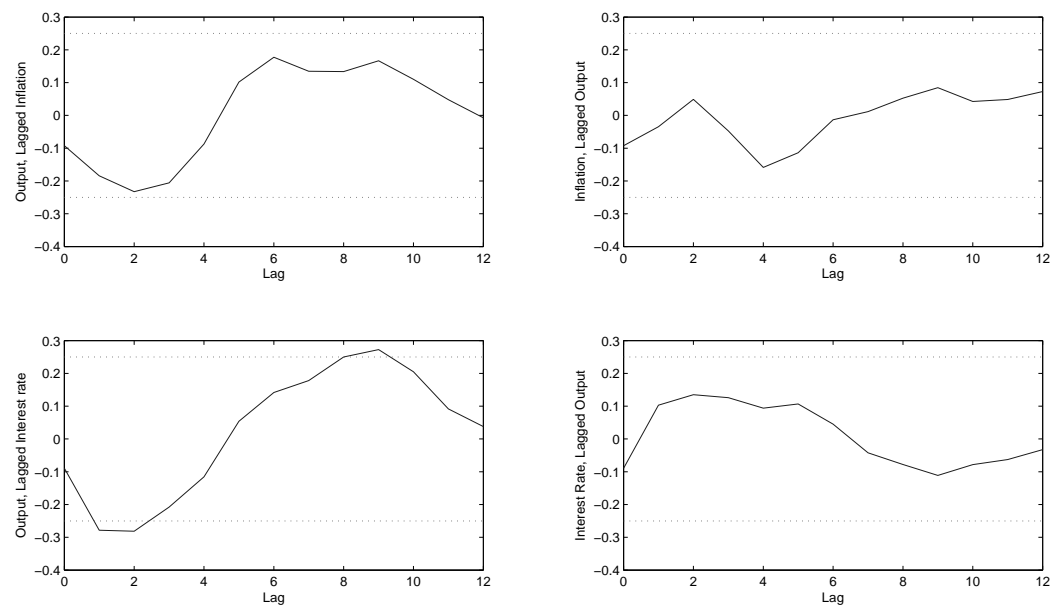

Figure 1: Cross Correlations - HP Filter - Brazil 

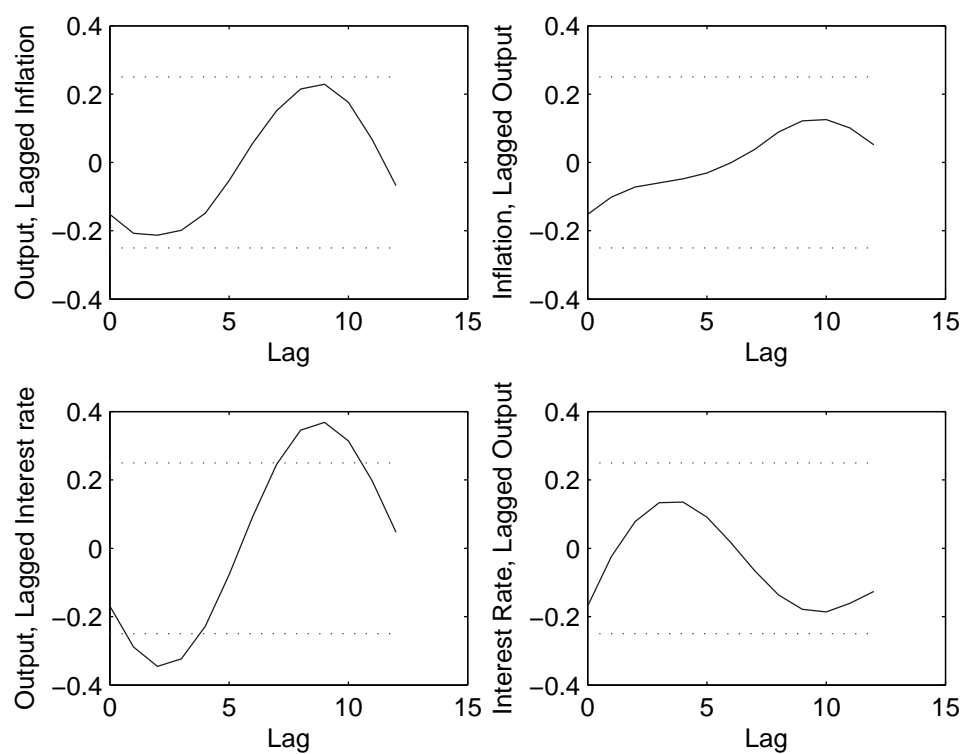

Figure 2: Cross Correlations - CF Band Pass Filter - Brazil

\subsection{U.S.}

I use the same quarterly sample as Cassou \& Vázquez (2010), starting in the first quarter of 1965 and ending in the last quarter of 2008. The data comes from the FRED database of the Federal Reserve Bank of Saint Louis. The measure of inflation is the log difference in GDP deflator and the interest rate is the Fed Funds rate. I use the output gap measure based on real GDP data as computed by the Bureau of Economic Analysis. In all figures, since the sample is relatively large, I report the approximate asymptotic two standard error bounds to identify in which lags the dynamic correlations are statistically different from zero, taking therefore into account the uncertainty in the estimated correlations.

For the U.S., the dynamic correlations between the output gap and inflation show that high inflation anticipates lower levels of output gap from three to eleven quarters later. Further, high interest rates also anticipate lower output gaps. These effects are statistically significant. In addition, the output gap positively leads inflation from one to eight quarters. This is also true for the interest rates. Again, these positive dynamic correlations are statistically significant. These results are consistent with the empirical evidence reported in Fuhrer \& Moore (1995b) and in Cassou \& Vázquez (2010), and the dynamic correlations concerning the output gap and inflation are in line with the findings in Wang \& Wen (2007). Moreover, they are robust to alternative filtering techniques.

The contemporaneous correlation between the output gap and inflation and the contemporaneous correlation between the output gap and the interest rate are both positive. 

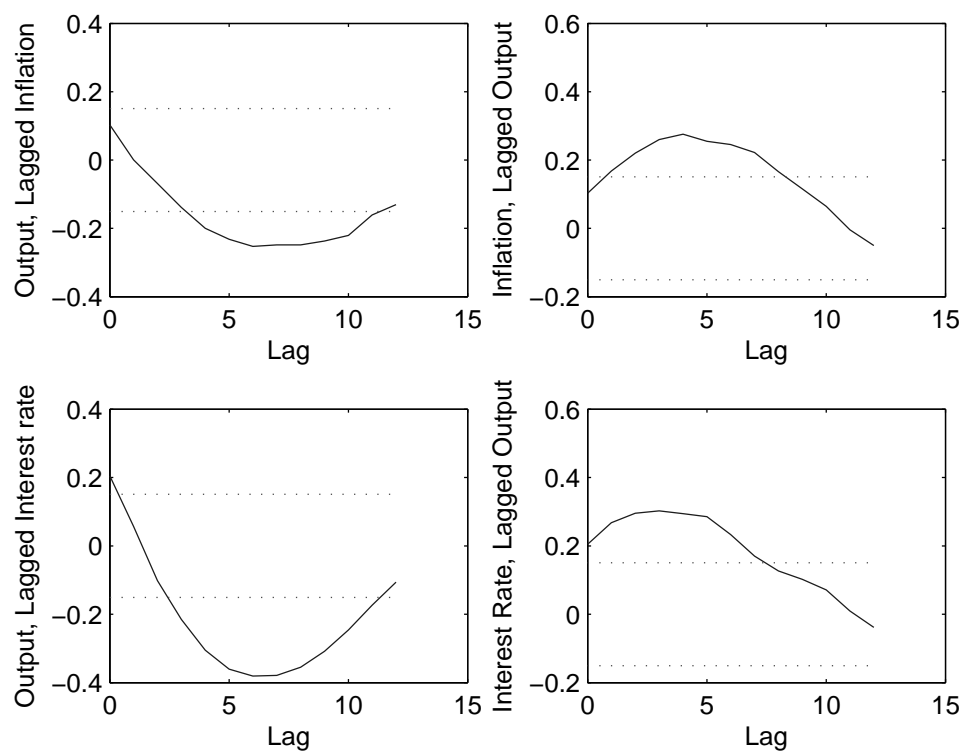

Figure 3: Cross Correlations - HP Filter - U.S.
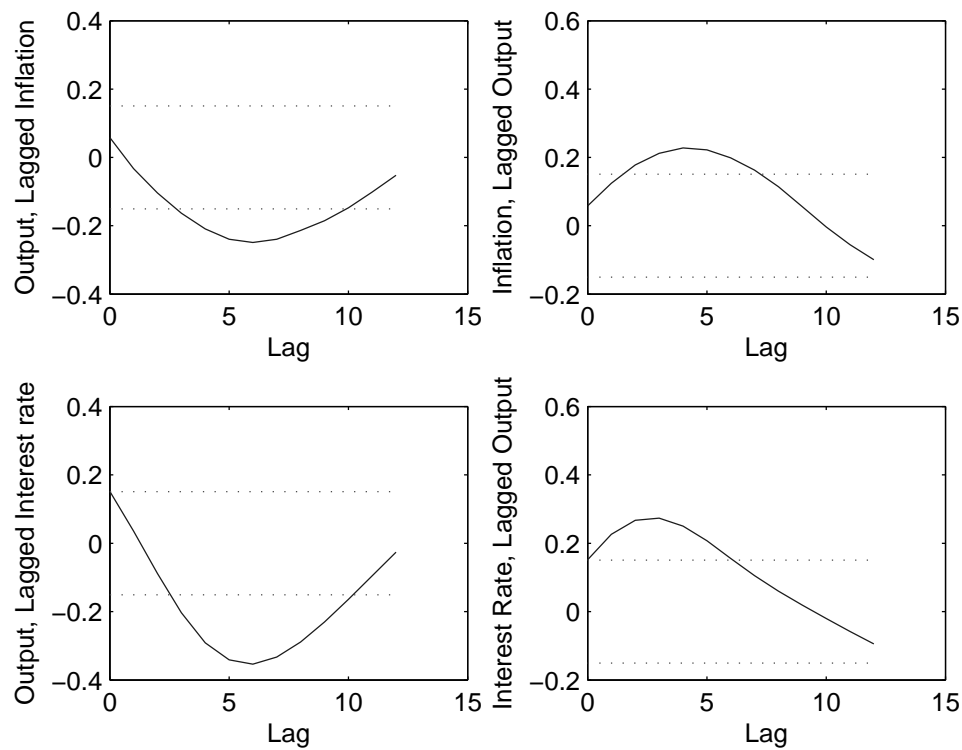

Figure 4: Cross Correlations - CF Band Pass Filter - U.S. 


\subsection{Discussion}

The dynamic correlation patterns for Brazil are different from the U.S. Differences in the degree of economic development, institutional arrangements and country's history might explain the diversity in the dynamic correlations behavior reported in 2.1 and 2.2. Another important feature probably driving the results is the very short sample considered in the case of Brazil, covering quarterly data from the period of stable inflation.

Moreover, there isn't a priori reasoning justifying the absence of countrydependence in establishing a set of stylized facts concerning cross-correlations. Dynamic correlation patterns tend to be heterogeneous even if the countries studied are more homogeneous. Indeed, for 18 OECD countries, the crosscorrelations between the output gap and inflation reported in Wang \& Wen (2007) support this claim.

In the following sections, I will ask if variants of the new Keynesian model can match at least qualitatively the patterns described in 2.1 and 2.2.

\subsection{The Models}

In this section, I briefly describe the artificial economies studied. Since the specifications feature standard building blocks which previous research used extensively, I describe the structure of the model with more details in the appendix. Rather than describe each economic agent and its constraints in this section, I provide references that discuss the specifics of the new Keynesian framework I use in this paper, referring the reader to the appendix for further details.

Galí (2008) presents the basic new Keynesian model in chapter 3. The extended version with habit formation follows the discussion in Dennins (2009). To be more specific, I use the multiplicative habit specification described in Fuhrer (2000). The period utility function is $u\left(C_{t}\right)=\frac{1}{1-\frac{1}{\tau}}\left(\frac{C_{t}}{C_{t-1}^{\gamma}}\right)^{1-\frac{1}{\tau}}$. Dennins (2009) compares alternative strategies to modeling habit formation and concludes that up to a first order approximation, business cycle properties are independent of the chosen approach to modeling habit formation. Dennins (2009), however, does not address the issue concerning the role of habit formation for the co-movement between real and nominal variables.

Galí \& Gertler (1999) discussed extensively the hybrid version of the new Keynesian Phillips Curve. I use the version based on dynamic indexation proposed by Smets \& Wouters (2003), which Dennins (2009) uses to complete the supply-side of the models he discussed.

The following expressions describe the log-linear approximations of the first order conditions characterizing the equilibrium in the extended version of the new Keynesian model with habit persistence and a hybrid new Keynesian Phillips curve.

$$
\begin{gathered}
{\left[\left[\tau+\frac{1+\beta \gamma^{2}+\gamma}{1-\beta \gamma}(1-\tau)\right] y_{t}=\frac{\gamma(1-\tau)}{1-\beta \gamma} y_{t-1}+\left[\tau+\frac{1+\beta \gamma(1+\gamma)}{1-\beta \gamma}(1-\tau)\right] E_{t} y_{t+1}\right]} \\
+\frac{\beta \gamma(1-\tau)}{1-\beta \gamma} E_{t} y_{t+2}-\tau\left(i_{t}-E_{t} \pi_{t+1}\right)+g_{t} \\
\pi_{t}=\frac{\beta}{1+\omega \beta} E_{t} \pi_{t+1}+\frac{\kappa}{1+\omega \beta} y_{t}+\frac{\omega}{1+\omega \beta} \pi_{t-1}+z_{t}
\end{gathered}
$$


I use the following notation: $y_{t}, \pi_{t}$, and $i_{t}$ denote the output gap and the deviations from the steady states of inflation and interest rates, respectively. The condconclusiitional expectation operator based on the information set available to agents at time $t$ is $E_{t}$. In addition, $g_{t}$ and $z_{t}$ stand for aggregate demand and supply shocks. These shocks follow first-order auto-regressive processes:

$$
\begin{aligned}
g_{t} & =\rho_{g} g_{t-1}+\varepsilon_{g t} \\
z_{t} & =\rho_{z} z_{t-1}+\varepsilon_{z t}
\end{aligned}
$$

The shocks $\varepsilon_{g t}$ and $\varepsilon_{z t}$ are normally distributed random variables with mean zero and variances $\sigma_{g}^{2}$ and $\sigma_{z}^{2}$, respectively.

Equation 1 is the log-linear approximation of the consumption Euler equation with the specification of habit formation described in Fuhrer (2000). The parameter $\beta$ is the inter-temporal discount factor of the representative consumer. The pconclusiarameter $\tau$ is the inverse of the relative risk aversion parameter in a constant relative risk aversion utility function. Finally, the parameter $\gamma$ measures the degree of habit persistence. The absence of habit formation is the situation in which $\gamma=0$ and, consequently, the inertial term in the Euler equation vanishes.

Equation 2 is a hybrid new Keynesian Phillips curve in which $\omega$ is the fraction of firms in the Calvo (1983) set up that can revise their prices according to lagged inflation, though unable to re-optimize them. The absence of inertia in inflation is the situation in which $\omega=0$, and equation 2 becomes the canonical new Keynesian Phillips curve.

The following Taylor-type rules describe monetary policy.

$$
\begin{gathered}
i_{t}=\rho i_{t-1}+(1-\rho)\left(\psi_{1} \pi_{t}+\psi_{2} y_{t}\right)+v_{t} \\
i_{t}=\rho i_{t-1}+(1-\rho)\left(\psi_{1} E_{t} \pi_{t+1}+\psi_{2} E_{t} y_{t+1}\right)+v_{t}
\end{gathered}
$$

Equation 3 is an interest rate rule in which the central bank responds contemporaneously to $\pi_{t}$ and $y_{t}$. Equation 4 is an interest rate rule in which the central bank responds to forecasts of inflation and the output gap, denoted by $E_{t} \pi_{t+1}$ and $E_{t} y_{t+1}$. In both specifications, the parameter $\rho$ captures interest rate persistence. The coefficients of the Taylor rule are $\psi_{1}$ and $\psi_{2}$, and $v_{t}$ denotes a normally distributed monetary policy shock with variance $\sigma_{v}^{2}$.

The contemporaneous Taylor rule, described in equation 3, was used in Paez-Farrell (2007, 2008), María-Dolores \& Vázquez (2008) and Cassou \& Vázquez (2010). To isolate the effects of habit persistence under alternative price-setting specifications and to compare the results with these previous papers, I characterize monetary policy as specified in equation 3. I also consider a forward-looking specification. The motivation to study models' behavior under a forward-looking Taylor rule is mainly empirical. In fact, Gertler et al. (1998) show that empirical evidence supports a forward-looking Taylor rule as the best description of central bank's behavior for the G3 countries (U.S., Germany and Japan). Additionally, as I consider a calibration based on Brazilian data, which is an explicit inflation-targeting country since 1999, I introduce, in the Taylor rule, an explicit role for inflation expectations, which some economists view as extremely relevant under inflation-targeting regimes. 
In addition to the new Keynesian Phillips curve described in equation 2, based on a sticky price model of price-setting behavior, I consider a version of the Phillips curve based on Mankiw \& Reis (2002). The basic idea is that information disseminates slowly in the economy. In each period, a fraction $\lambda$ of firms obtains new information on the state of the economy and computes optimal prices based on this information. The fraction $1-\lambda$ of firms continues to set prices based on outdated information. The assumption about information arrival is analogous to the assumption about price-stickiness in the traditional sticky-price model of Calvo (1983). The following expression describes the sticky-information Phillips curve.

$$
\pi_{t}=\left(\frac{\lambda \alpha}{1-\lambda}\right) y_{t}+\lambda \sum_{j=0}^{\infty}(1-\lambda)^{j} E_{t-1-j}\left[\pi_{t}+\alpha\left(y_{t}-y_{t-1}\right)\right]+z_{t}
$$

The parameter $\alpha$ connects real marginal costs to the output gap, and usually depends on the specification of the utility function in the case of constant returns to scale technology using only labor as input. Under sticky information, I drop equation 2 from the system and, instead, use 5 as a description of the supply side of the model.

The results in Paez-Farrell $(2007,2008)$, as well as in María-Dolores \& Vázquez (2008), emphasize that the structure of the canonical new Keynesian model leads to more important effects of aggregate supply shocks relative to aggregate demand shocks. One way to generate co-movement is to specify an empirically implausible ratio between the variances of these shocks. An alternative strategy is to alter some structural features of the canonical model to induce larger effects of aggregate demand shocks vis-à-vis aggregate supply shocks. The introduction of habit formation and a forward-looking Taylor rule increases the relative importance of aggregate demand shocks, allowing more forward-looking agents to react instantly to demand related shocks. Larger effects of aggregate demand shocks will also depend on which type of rigidity is driving inflation dynamics in a particular model. Therefore, it is important to consider alternative inflation dynamics theories (sticky prices or sticky information). 111

\section{Results}

\subsection{Calibration}

I consider the specifications described in table 1 and table 2. Table 1 concerns the sticky-price version of the model. The first specification, in this table, denoted by Model 1, is the canonical new Keynesian model, without habit formation $(\gamma=0)$, without a backward-looking component in inflation $(\omega=0)$ and with a contemporaneous Taylor rule featuring interest rate smoothing as in equation 3. Model 2 has no habit formation $(\gamma=0)$, a hybrid new Keynesian Phillips curve, and a contemporaneous Taylor rule featuring interest rate smoothing as in equation 3. Model 3 has an Euler equation with habit formation, a hybrid new Keynesian Phillips curve, and a contemporaneous Taylor rule featuring interest rate smoothing as in equation 3. Finally, Model 4 has0 the same structural characteristics as Model 3, but monetary policy follows a forecast-based Taylor rule featuring interest rate smoothing as in equation 4 . 
Table 2 shows the specifications I consider under sticky-information. The first specification, in this table, denoted by Model 5, has no habit formation $(\gamma=0)$, and a contemporaneous Taylor rule featuring interest rate smoothing as in equation 3. Model 6 has an Euler equation with habit formation and a contemporaneous Taylor rule featuring interest rate smoothing as in equation 3. Model 7 has the same structural characteristics as Model 6, but monetary policy follows a forecast-based Taylor rule featuring interest rate smoothing as in equation 4 . Table 3 summarizes the parameterization I use for the different specifications of the model.

Brazil

To calibrate the new Keynesian model, I take parameter values for $\beta, \omega$ and $\kappa$ from Silveira (2008), who estimated a DSGE model using Brazilian data. I also use his estimation for the Taylor rule parameters. The high value for $\gamma$, around 0.6, reported in Silveira (2008) induced indeterminacy. Therefore, I calibrate this parameter with the same magnitude used in the US case. These values are consistent with estimated values reported in McDermott \& McMenamin (2008) for a semi-structural new Keynesian model fitted to Latin American countries in the post inflation-target regime. The parameters for the sticky information Phillips Curve come from Caetano \& Moura (2009). These parameters are actually the mean values for the estimated parameters that they report under different settings. The shocks' calibration follows Bugarin \& Freitas (2007).

The U.S.

Following María-Dolores \& Vázquez (2008), I calibrate the parameters according to the estimates in Lubik \& Schorfheide (2004). The U.S. calibration follows tables 1 and 3 in María-Dolores \& Vázquez (2008). The degree of habit persistence is slightly different from 0.25 , reported in María-Dolores \& Vázquez (2008). For the sticky information model, I follow the calibration in Mankiw \& Reis (2002) concerning the parameters governing inflation dynamics.

Table 1: Specifications for the Sticky-Price Model

\begin{tabular}{llll}
\hline Models & Habit Formation & Hybrid NK Phillips & Forward Taylor \\
\hline 1 & NO $(\gamma=0)$ & NO $(\omega=0)$ & NO (eq. 3) \\
2 & NO $(\gamma=0)$ & YES $(\omega>0)$ & NO (eq. 3) \\
3 & YES $(\gamma>0)$ & YES $(\omega>0)$ & NO (eq. 3) \\
4 & YES $(\gamma>0)$ & YES $(\omega>0)$ & YES (eq. 4) \\
\hline
\end{tabular}

\subsection{Findings}

I present results concerning dynamic correlations between output and nominal variables for the models. I then compare the dynamic correlations from the simulations of the models with the co-movement statistics based on data as reported in section 2 of this paper. I have computed confidence bands based on 5000 simulations. The goal is to assess if the models are able to generate 
Table 2: Specifications for the StickyInformation Model

\begin{tabular}{lll}
\hline Models & Habit Formation & Forward Taylor \\
\hline 5 & NO $(\gamma=0)$ & NO (eq. 3) \\
6 & YES $(\gamma>0)$ & NO (eq. 3) \\
7 & YES $(\gamma>0)$ & YES (eq. 4) \\
\hline
\end{tabular}

Table 3: Calibration

\begin{tabular}{|c|c|c|}
\hline Parameter Values & Brazil & U.S. \\
\hline \multicolumn{3}{|c|}{ Aggregate Demand Equation } \\
\hline$\tau$ & 0.5000 & 0.5376 \\
\hline$\beta$ & 0.9758 & 0.9926 \\
\hline$\gamma$ & 0.3000 & 0.3000 \\
\hline \multicolumn{3}{|c|}{ New Keynesian Phillips Curve } \\
\hline$\kappa$ & 0.0160 & 0.5800 \\
\hline$\omega$ & 0.4500 & 0.2000 \\
\hline \multicolumn{3}{|c|}{ Sticky-Information Phillips Curve } \\
\hline$\alpha$ & 0.1500 & 0.1000 \\
\hline$\lambda$ & 0.1700 & 0.2500 \\
\hline \multicolumn{3}{|c|}{ Taylor Rule } \\
\hline$\rho$ & 0.6000 & 0.8400 \\
\hline$\psi_{1}$ & 1.5000 & 2.1900 \\
\hline$\psi_{2}$ & 0.8000 & 0.3000 \\
\hline \multicolumn{3}{|c|}{ Stochastic Disturbances } \\
\hline$\rho_{g}$ & 0.3400 & 0.8300 \\
\hline$\sigma_{g}$ & 0.1500 & 0.1800 \\
\hline$\rho_{z}$ & 0.7000 & 0.8500 \\
\hline$\sigma_{z}$ & 0.0300 & 0.6400 \\
\hline$\sigma_{v}$ & 0.1200 & 0.1800 \\
\hline
\end{tabular}


values for dynamic correlations compatible with the ones based on a finite sample. Therefore, for each specification described in tables 1 and 2, I will assess if the observed dynamic correlations are within the confidence bands generated by the model.

Figures 5 to 18 present the dynamic correlations between output and two nominal variables (inflation and interest rates) for Brazil (figures 5 to 11) and for the U.S. (figures 12 to 18). The figures report lower and upper bounds based on $95 \%$ confidence intervals (dotted lines). For each specification, I obtain these bounds from simulated time series. The circled line denotes observed dynamic correlations in which I use the Hodrick-Prescott (HP) filter to compute the output gap. The $\mathrm{x}$-marked lined denotes observed dynamic correlations in which I use the Christiano and Fitzgerald filter (CF) to compute the output gap. The solid line represents the average dynamic correlations across simulations.

\section{Brazil}

Figures 5 to 11 show the results for Brazil. The first remark is that the confidence bands generated by simulation are very large. Therefore, in a statistical sense, the models are capable of generating the cross-correlation pattern observed at least for lags greater than 3 .

In the standard new Keynesian model, this is the case even for short lags. The introduction of a hybrid Phillips curve or habit persistence, in the new Keynesian specifications, makes the upper bound for the correlations very negative for short lags. This is not consistent with the small negative magnitudes of the cross-correlations for short lags. Interestingly, the new Keynesian models capture very well the cross-correlations between inflation and lagged output for lags greater than 4 . In addition, the magnitudes of the correlations between output and lagged inflation, as well as the correlations between output and lagged interest rates, tend to be higher in the data compared to the mean across simulations, especially for long lags.
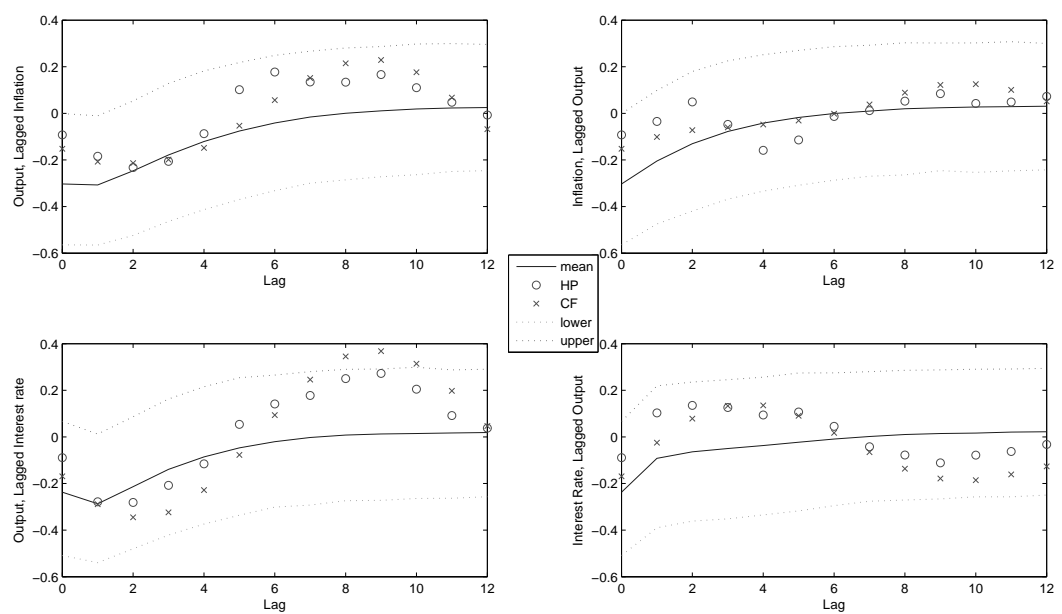

Figure 5: Brazil Model 1 (sticky price, no habit, no hybrid and no forward) 

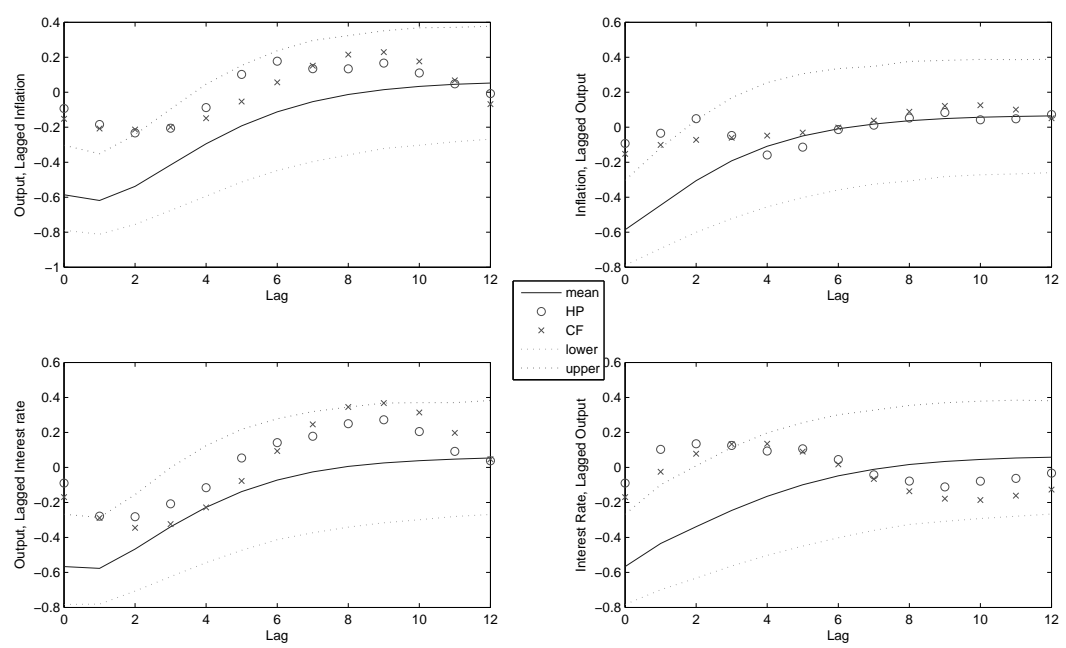

Figure 6: Brazil Model 2 (sticky price, no habit, hybrid and no forward)
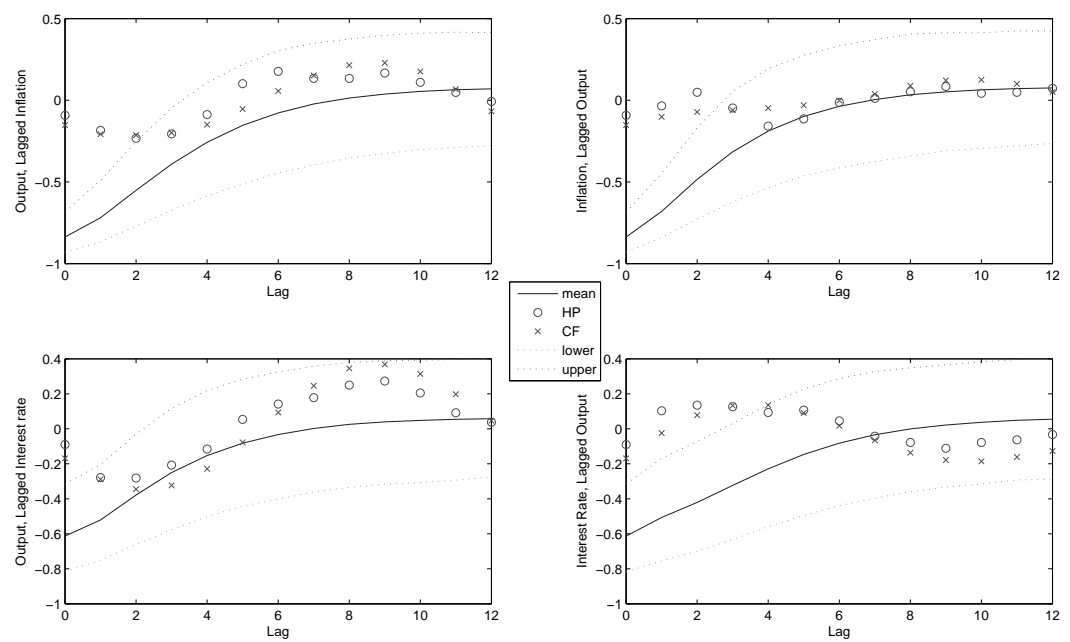

Figure 7: Brazil Model 3 (sticky price, habit, hybrid and no forward) 

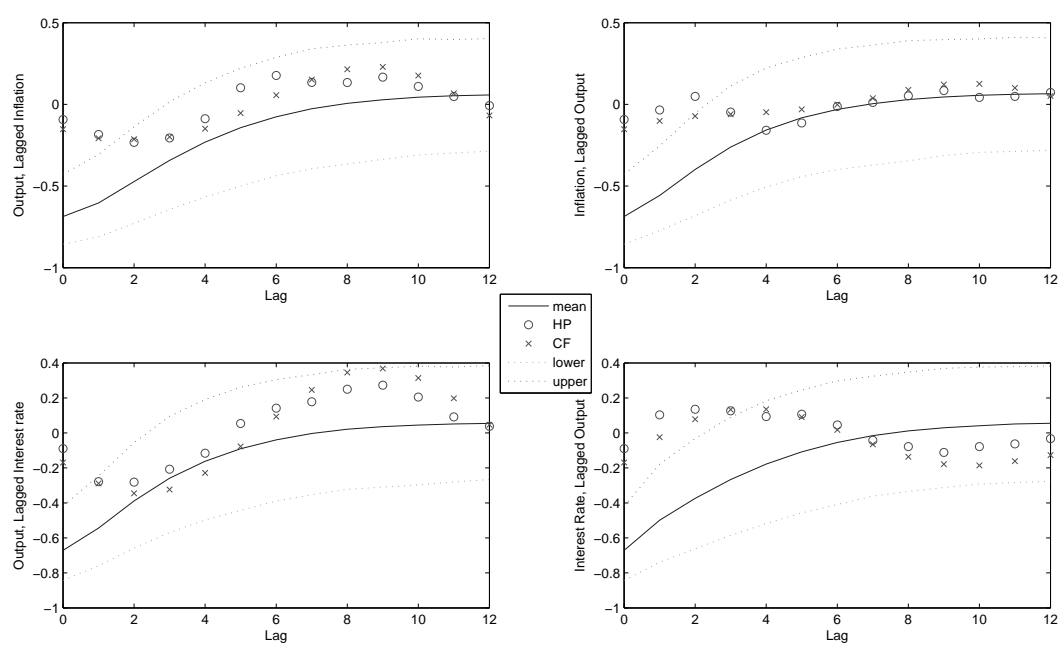

Figure 8: Brazil Model 4 (sticky price, habit, hybrid and forward)

For almost all lags, the sticky information models, irrespective of exhibiting habit persistence or a forward-looking Taylor rule, are consistent with the observed cross-correlations. In fact, the upper bounds are positive or mildly negative. In spite of that fact, the empirical correlations tend to be more disperse relatively to mean of the simulations. In fact, the mean of the simulated correlations between output and lagged inflation, as well as the correlations between output and lagged interest rates, are flatter in the sticky information specifications compared to the sticky price models, especially for long lags.
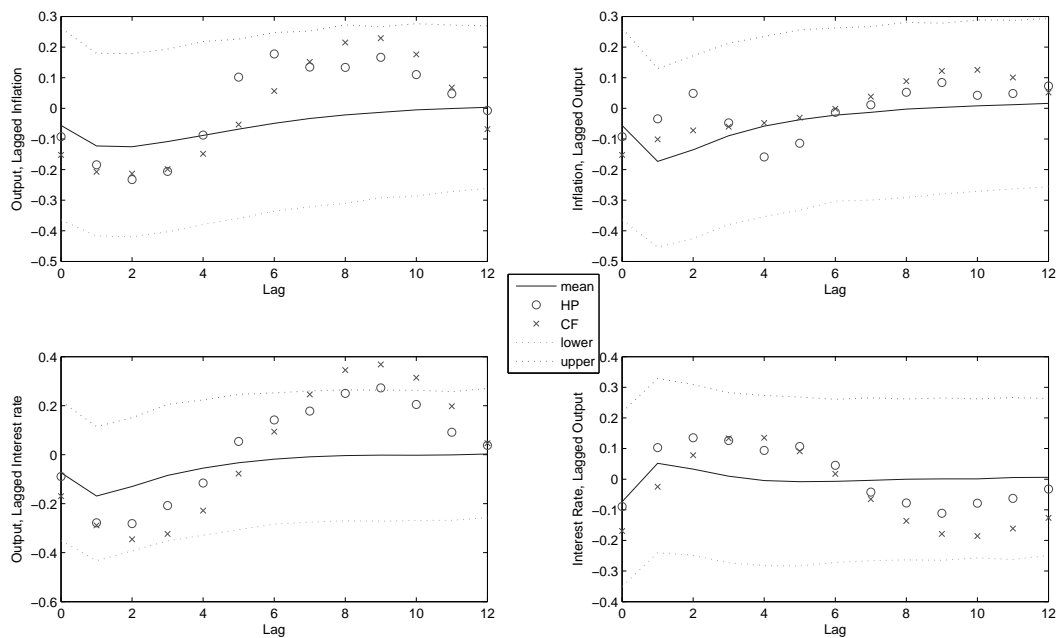

Figure 9: Brazil Model 5 (sticky information, no habit and no forward) 


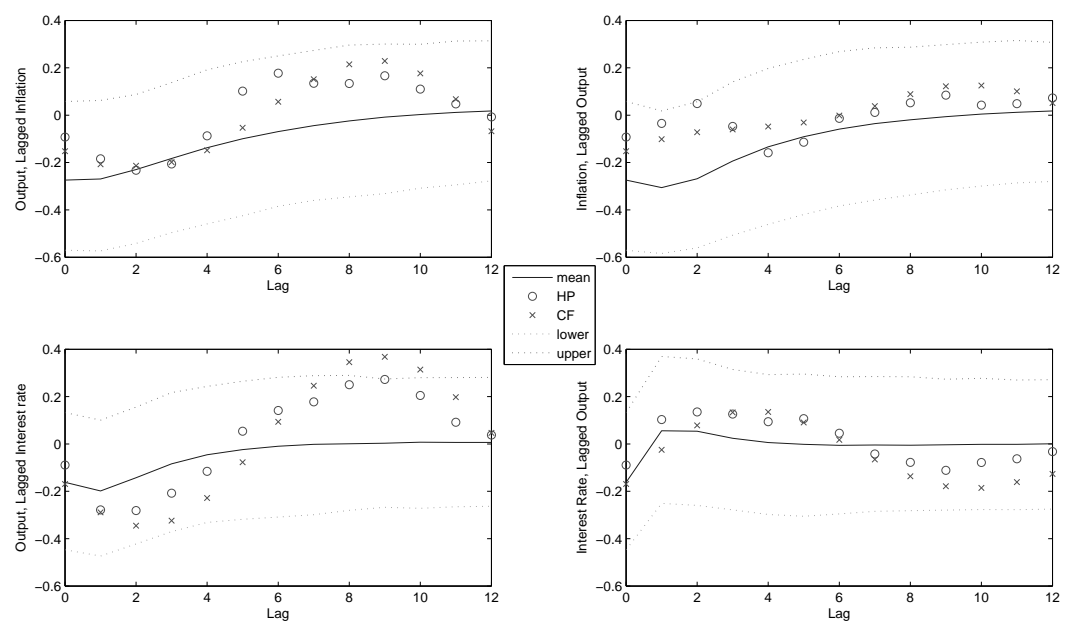

Figure 10: Brazil Model 6 (sticky information, habit and no forward)

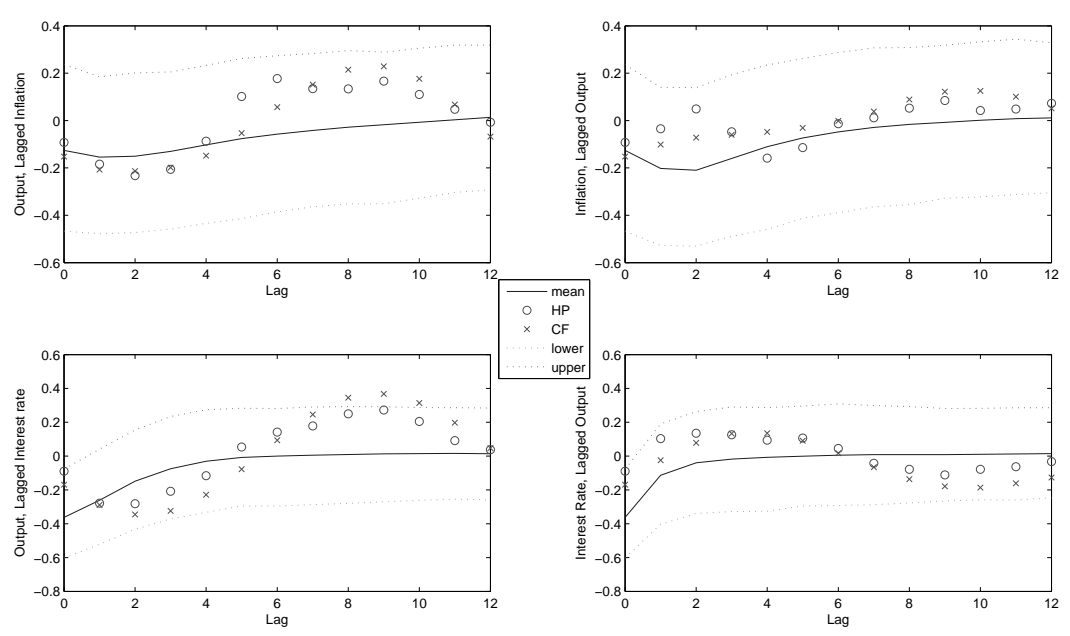

Figure 11: Brazil Model 7 (sticky information, habit and forward) 
U.S.

Figures 12 to 18 show the results associated with the U.S. economy. Figures 12 to 15 report the dynamic correlations for the sticky price models. Model 1 predicts a very strong negative co-movement in all lags. Therefore, the canonical new Keynesian specification cannot account for the dynamic correlations between output and nominal variables. Paez-Farrell (2008) documents very well this inability of the canonical new Keynesian model.

The introduction of backward-looking terms, first in the Phillips Curve and next in the dynamic Euler equation (the IS curve), does not change that characteristic very much. The forward-looking Taylor rule does not help either. The models, however, are able to match the dynamic correlation patterns for long lags, since they are negative. In fact, for the correlation between the output gap and lagged nominal variables, the observed values are within the bands for lags approximately greater than four. The observed correlations between nominal variables and the lagged output gap lie inside the bands for lags approximately greater than seven. On the other hand, the positive values for the correlations associated with short lags are difficult to match.
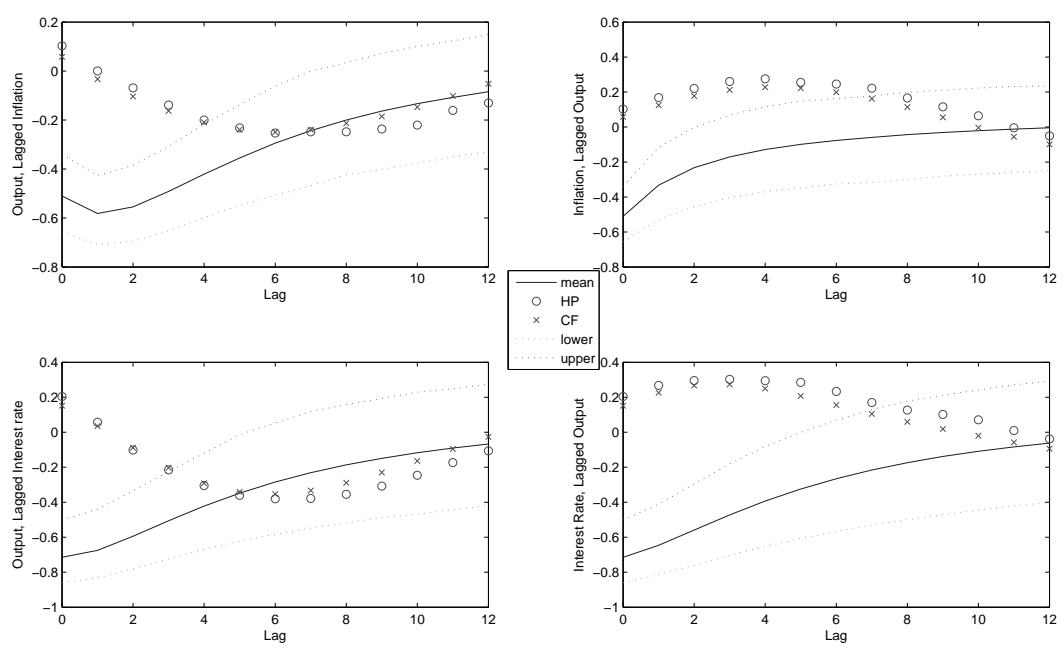

Figure 12: U.S. Model 1 (sticky price, no habit, no hybrid and no forward)

Figures 16 to 18 present results concerning the sticky information model. The conventional sticky information model without habit formation generates strong negative correlations. These correlations are stronger than the ones related to sticky price models. With the introduction of habit persistence, the dynamic cross correlations between the interest rate and the output gap became predominantly positive. In contrast to these strong positive correlations implied by the sticky information models with habit persistence, the observed values are only mildly positive for short lags. Therefore, the simulated dynamic correlations do not match the observed correlations. In spite of these facts, with habit persistence, the correlations based on simulated data between the output gap and lagged inflation are more in line with the observed correlations, since they are within the confidence bands. On the other 

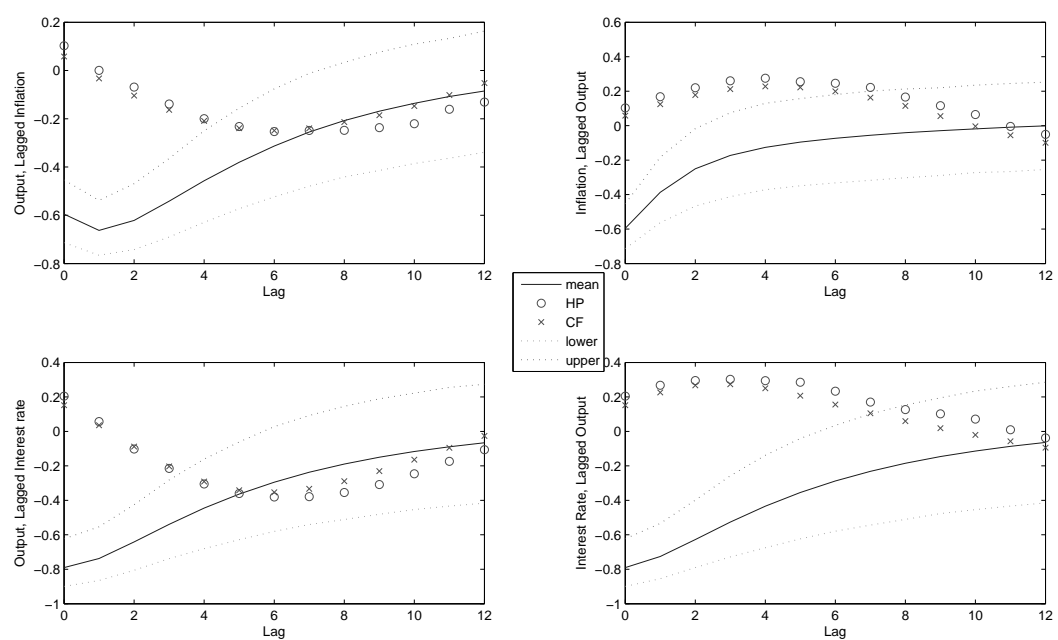

Figure 13: U.S. Model 2 (sticky price, no habit, hybrid and no forward)
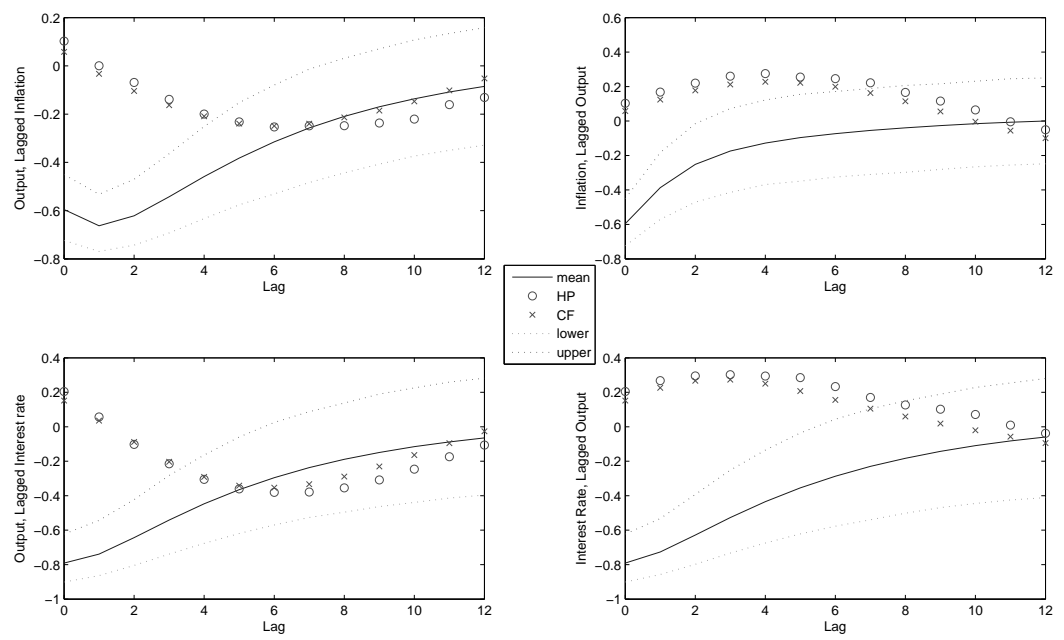

Figure 14: U.S. Model 3 (sticky price, habit, hybrid and no forward) 

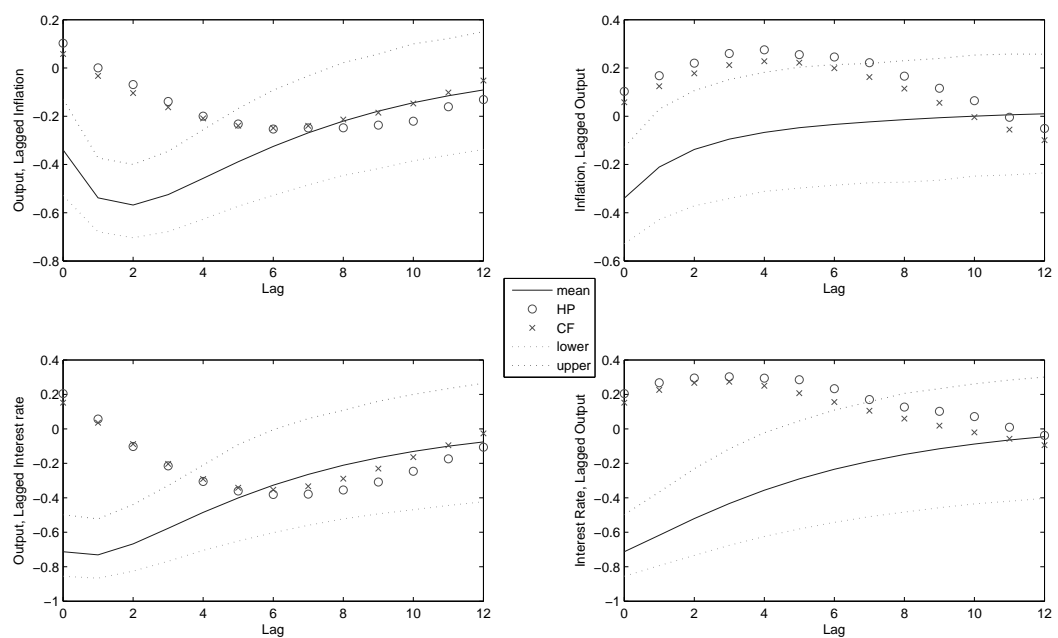

Figure 15: U.S. Model 4 (sticky price, habit, hybrid and forward)

hand, the models in figures 16 to 18 do not capture the correlations between lagged output and inflation. Finally, results in figure 17 do not change when I use a forward-looking Taylor rule in the simulations (figure 18).
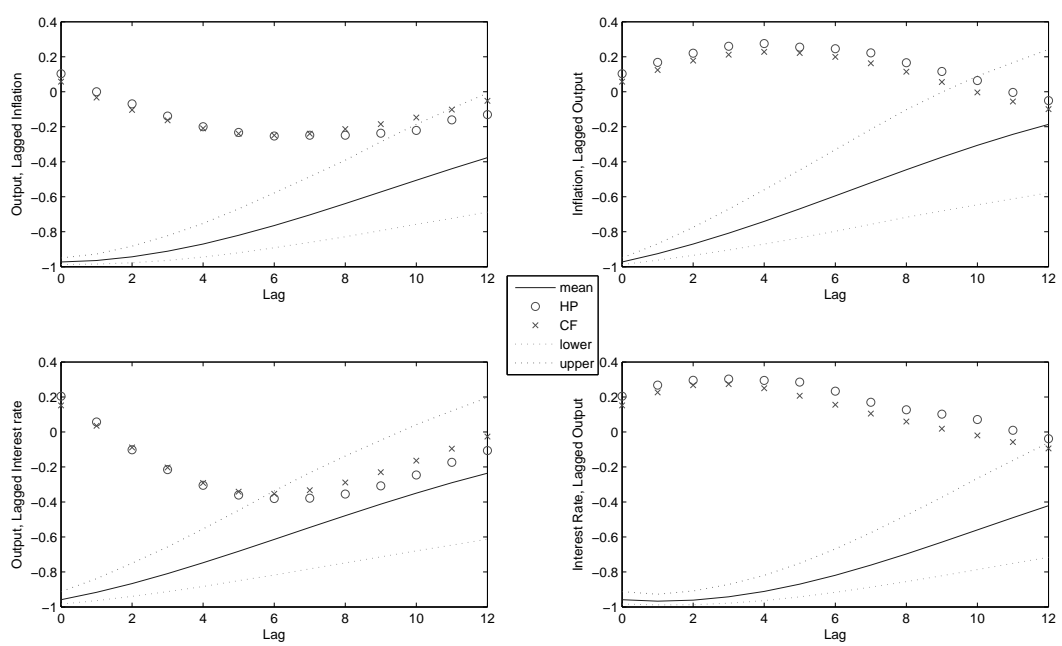

Figure 16: U.S. Model 5 (sticky information, no habit and no forward)

In sum, a conventional habit formation specification and a forward-looking Taylor rule are not enough to capture the dynamic relationship between inflation and the output gap. 

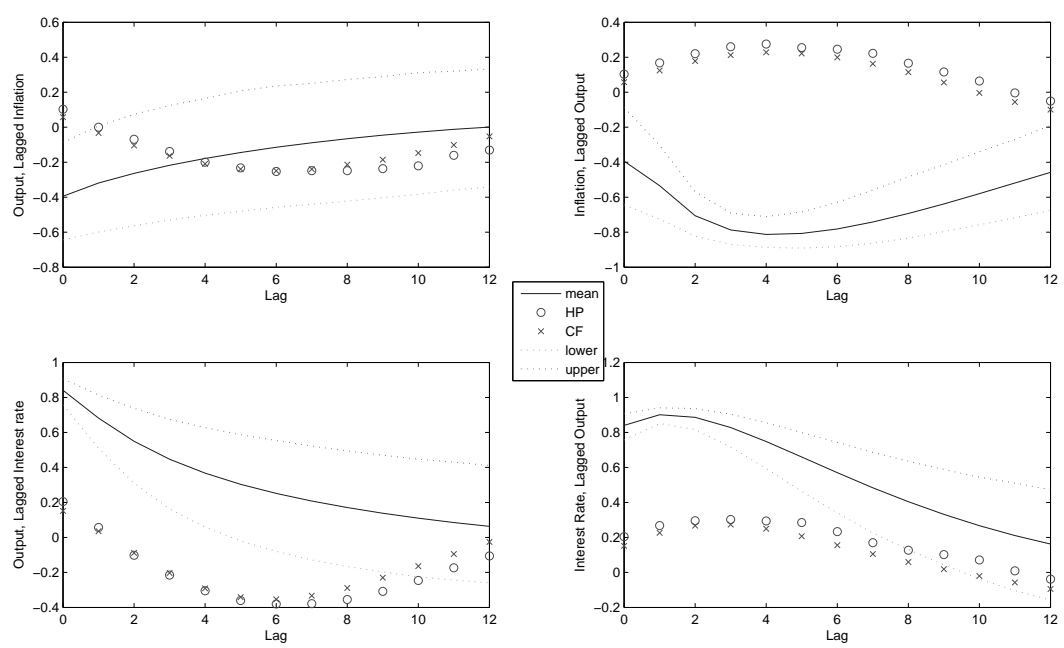

Figure 17: U.S. Model 6 (sticky information, habit and no forward)
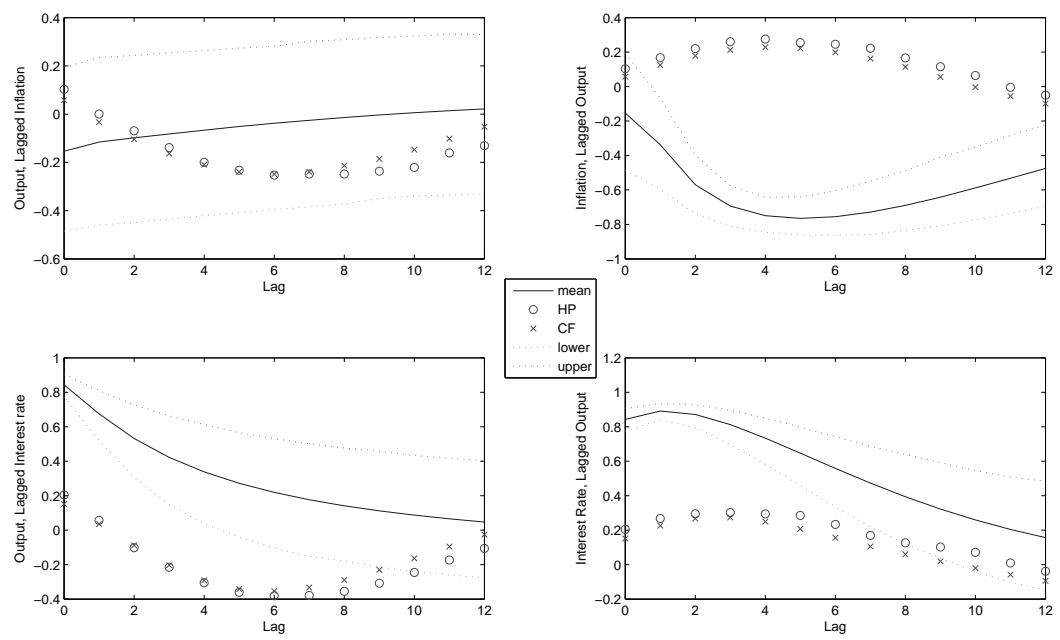

Figure 18: U.S. Model 7 (sticky information, habit and forward) 


\section{The Propagation of Shocks}

According to Cassou \& Vázquez (2010), impulse responses of key macroeconomic variables to demand $\left(\varepsilon_{g t}\right)$ and supply $\left(\varepsilon_{z t}\right)$ shocks can trace to some extent the pattern of lead and lag correlations. The difficult step in reproducing the cross-correlations pattern is to achieve the right balance between these shocks. In general, a variable $\mathrm{X}$ will lead a variable $\mathrm{Y}$ if the impact of a particular shock on $X$ dies out more quickly compared to the impact on Y. In contrast to Cassou \& Vázquez (2010), I do not calibrate the model to get the right correlation pattern. My goal is to assess the differences in impulse response functions between the sticky price and the sticky information models. I use the U.S. calibration and the model with all features that I am investigating with potential to enhance the ability of the models to induce a cross-correlation pattern more in line with the data. Thus, I am considering model 4 in table 1 and model 7 in table 2 as the specifications for impulse response analysis.

Figures 19 to 22 show impulse responses to demand and supply shocks to the models. The variables $y$, infla and $r$ denote output, inflation and the interest rate, respectively. According to figure 19, in the sticky price model, output leads the interest rate after a demand shock, but output and inflation seem to have approximately the same degree of persistence, therefore there is no tendency of lead-lag relationship between output and inflation. In addition, these variables move in the same directions after the shock. Figure 20 show the responses after a supply shock. All variables respond in a very persistent way, indicating that there is no tendency of lead-lag relationship between these variables. After the supply shock, output moves in the opposite direction compared to inflation and the interest rate, which increase after the supply shock.
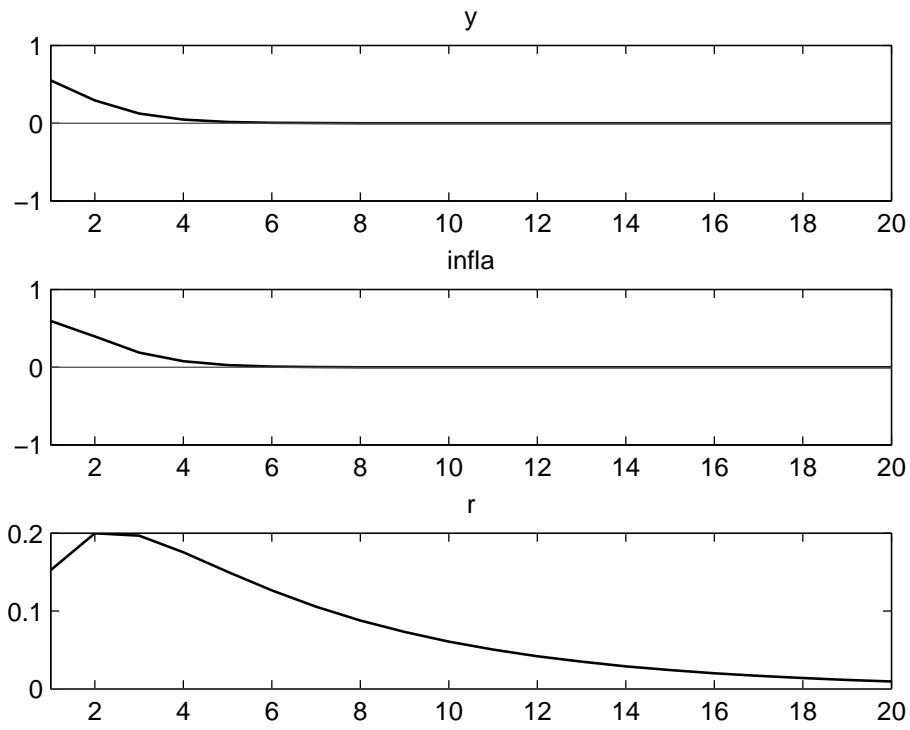

Figure 19: Impulse Response to demand shocks -sticky price model 

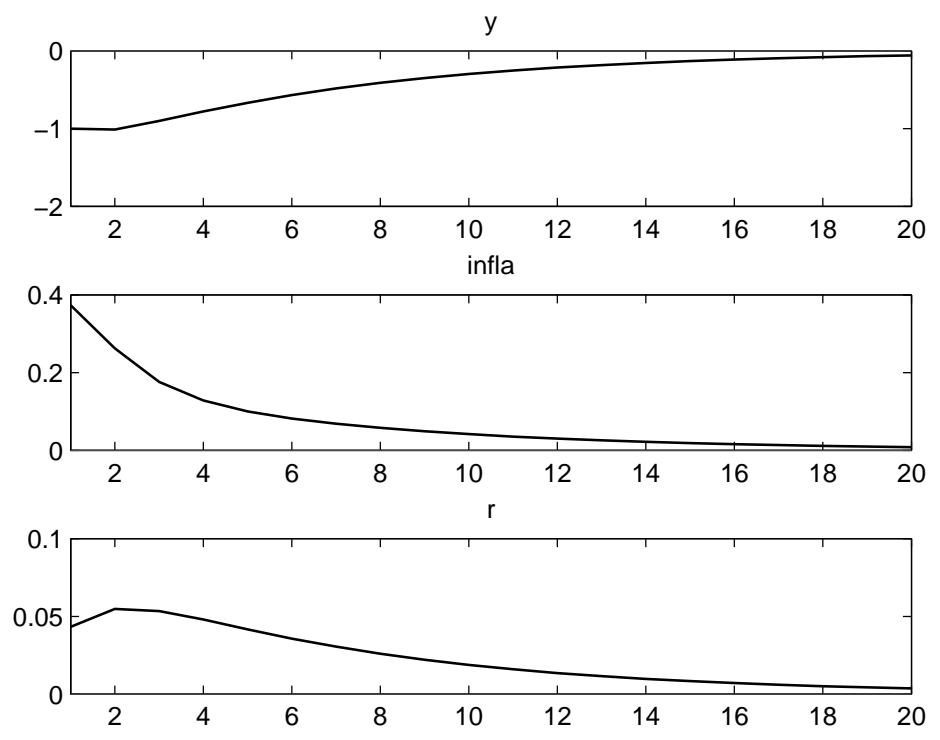

Figure 20: Impulse Response to supply shocks -sticky price model

Concerning the sticky information model, figure 21 shows that inflation tends to lead both output and the interest rate after a demand shock, since inflation is less persistent. Output and the interest rate display more or less the same degree of persistence. Again, all variables move in the same direction as in the sticky price model. Figure 22 shows impulse responses to the sticky information model after a supply shock. All variables respond in a very persistent way and the contraction in output is much stronger compared to the sticky price model, leading to a decrease in interest rates.

Though the qualitative pattern of response after a demand shock is similar across models, the comparative degree of persistence is not. In contrast to the sticky price model, the sticky information model delivers a different response pattern after a supply shock. This diversity in responses after demand and supply shocks, combined with different sizes for the variances of the shocks, explain the different shapes in cross-correlation functions from the alternative models discussed in 4.2 .

\section{Conclusions}

This paper extends the work in María-Dolores \& Vázquez (2008) and PaezFarrell (2008), and investigates if an extended version of the new Keynesian model featuring habit formation, forward-looking Taylor rules and alternative price schemes can mimic the dynamic correlations between output and two nominal variables (inflation and interest rates) in Brazil and in the U.S.

The models considered cannot offer a significant improvement in performance, compared to the canonical new Keynesian model. For Brazil, specifically, the simulated paths for the macroeconomic variables implied wide confidence intervals for cross-correlations. Furthermore, compared with the U.S. 

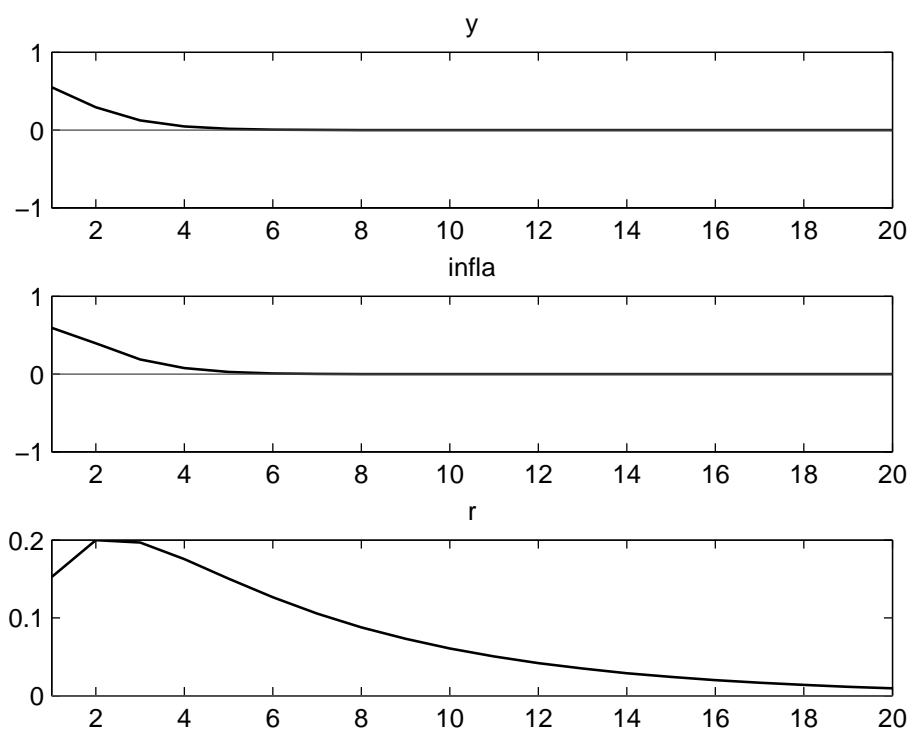

Figure 21: Impulse Response to demand shocks -sticky information model
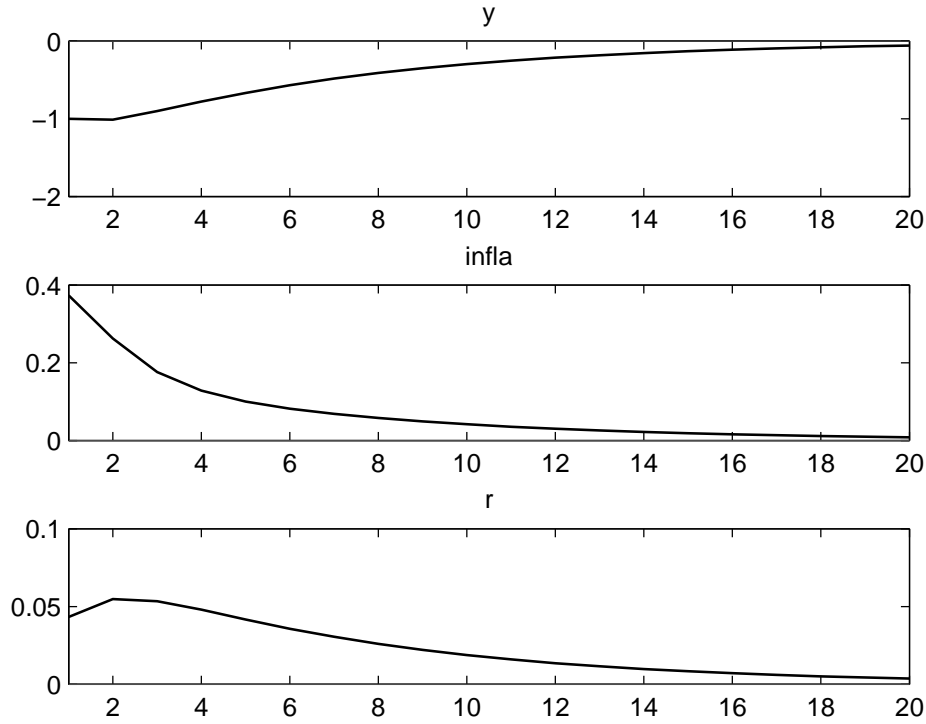

Figure 22: Impulse Response to supply shocks -sticky information model 
data, the extended models cannot reproduce the fact that inflation systematically lags output.

Compared with Cassou \& Vázquez (2010), I did not attempt to calibrate the models in order to match the lead and lag patterns concerning the dynamic correlation between output and nominal variables. Instead, I evaluated how alternative features not considered in Cassou \& Vázquez (2010) may improve the performance of macroeconomic models in replicating the dynamic cross-correlations between output and nominal variables. To this end, I used calibrations based on previously estimated parameters.

According to Cassou \& Vázquez (2010), the models need to get the right relative proportions for the supply and demand shock variances, as well as the relative persistence of these shocks. Since the results reported did not endorse a great improvement relatively to the basic new Keynesian model, in light of the findings in Cassou \& Vázquez (2010), supply and demand shocks were not in the right proportion in order to match the lead and lag patterns in the data for both countries.

Though Cassou \& Vázquez (2010) calibrated their model in order to match the dynamic correlation patterns, the parameter values they reported may be at odds with the data in other dimensions and may not be the most likely parameterization in a full-information context. Just to be more specific, the method these authors used was a limited-information approach, close to the simulated methods of moments, and there are multiple parameters configurations compatible with the lead and lag patterns in the data, therefore such calibration was not unique. Thus, it is prudent to regard the parameterizations reported by these authors with some degree of skepticism.

In short, in contrast to Cassou \& Vázquez (2010), I did not search for the parameters that would reproduce the patterns shown in the data. Instead, I used parameters from previous estimations, usually based on full information likelihood methods. In addition, I explored alternative features that could improve the basic new Keynesian model. The results show that these features alone under plausible calibrations are not enough to match the crosscorrelation patterns shown in the data with a good degree of accuracy. Thus, this paper corroborates Cassou \& Vázquez (2010), showing that a delicate combination between supply and demand shocks rather than the introduction of more structural or semi-structural features are extremely important in replicating the dynamic correlations between output and nominal variables.

This inability to reproduce important characteristics of the output-inflation dynamics seems to be a drawback of other models incorporating nominal, real or informational rigidities. Wang \& Wen (2007) show that alternative new Keynesian models, featuring sticky information or price stickiness, cannot match important characteristics of the output-inflation dynamics. The investigation of the joint implications of different forms of real and nominal rigidities for the co-movement between real and nominal variables seems to be a fruitful area for future research.

\section{Acknowledgements}

I gratefully acknowledge the financial support from the Brazilian Council of Science and Technology (CNPq). . I would like to thank three anonymous referees and the associate editor, Irineu de Carvalho Filho, for helpful comments 
and suggestions. The views expressed in this paper are my own and do not necessarily reflect those of the Banco Central do Brasil

\section{Bibliography}

Bugarin, M. \& Freitas, P. (2007), 'A study on administered prices and optimal monetary policy', SBE, XXIX Encontro Brasileiro de Econometria.

Caetano, S. \& Moura, G. (2009), 'Reajuste informacional no brasil: uma aplicação da curva de phillips sob rigidez de informação', ANPEC, XXXVII Encontro Nacional de Economia .

Calvo, G. (1983), 'Staggered prices in a utility-maximizing framework', Journal of Monrtary Economics 12, 383-398.

Cassou, S. \& Vázquez, J. (2010), 'New keynesian model features that can reproduce lead, lag and persistence patterns.'.

Christiano, L., Eichenbaum, M. \& Evans, C. (2005), 'Nominal rigidities and the dynamic effects of a shock to monetary policy,', Journal of Political Economy 113, 1-45.

Christiano, L. J. \& Fitzgerald, T. J. (2003), 'The band pass filter', International Economic Review 44, 435-465.

Coibion, O. (2010), 'Testing the sticky information phillips curve', The Review of Economics and Statistics, 92, 87-101.

Den Haan, W. J. (2000), 'The co-movement between output and prices', Journal of Monetary Economics 46, 3-30.

Dennins, R. (2009), 'Consumption habits in a new keynesian business cycle model', Journal of Money 41, 1015-1030.

Fuhrer, J. (2000), 'Habit formation and its implications for monetary policy models', American Economic Review 90, 367-390.

Fuhrer, J. C. \& Moore, G. R. (1995a), 'Inflation persistence', Quarterly Journal of Economics 110(1), 127-159.

Fuhrer, J. C. \& Moore, G. R. (1995b), 'Monetary policy trade-offs and the correlation between nominal interest rates and real output', The American Economic Review 85(1), 219-239.

Galí, J. (2008), Monetary Policy, Inflation, and the Business Cycle. An Introduction to the New Keynesian Framework.

Galí, J. \& Gertler, M. (1999), 'Inflation dynamics: A structural econometric analysis', Journal of Monetary Economics 44, 195-222.

Gertler, R. C., Gali, J. \& M. (1998), 'Monetary policy rules in practice: some international evidence', European Economic Review 42(6), 1033-1067.

Klein, P. (2000), 'Using the generalized schur decomposition form to solve a multivariate linear rational expectations model', Journal of Economic Dynamics and Control 24, 1405-1423. 
Kydland, F. \& Prescott, E. (1990), Business Cycles: Real Facts and a Monetary Myth, Federal Reserve Bank of Minneapolis.

Lubik, T. \& Schorfheide, F. (2004), 'Testing for indeterminacy: an application to us monetary policy,', American Economic Review 94, 190-217.

Mankiw, N. G. \& Reis, R. (2002), 'Sticky information versus sticky prices: A proposal to replace the new keynesian phillips curve,', The Quarterly Journal of Economics, 117, 1295-1328.

María-Dolores, R. \& Vázquez, J. (2008), 'The new keynesian monetary model: Does it show the comovement between gdp and inflation in the us?', Journal of Economic Dynamics 32, 1466-1488.

McDermott, J. \& McMenamin, P. (2008), 'Assessing inflation targeting in latin america with a dsge model', Central Bank of Chile Working Paper.

Paez-Farrell, J. (2007), 'Output and inflation in models of the business cycle with nominal rigidities: further counterfactual implications', Scottish Journal of Political Economy 54, 475-491.

Paez-Farrell, J. (2008), 'Assessing sticky price models using the burns and mitchell approach', Applied Economics 40, 1387-1397.

Silveira, M. (2008), 'Using a bayesian approach to estimate and compare new keynesian dsge models for the brazilian economy: the role for endogenous persistence.', Revista Brasileira de Economia, 62, 333-357.

Smets, F. \& Wouters, R. (2003), 'An estimated stochastic dynamic general equilibrium model of the euro area', Journal of the European Economic Association 1, 1123-1175.

Wang, P. \& Wen, Y. (2007), 'Inflation dynamics: A cross-country investigation', Journal of Monetary Economics 54, 2004-2031.

\section{Appendix A The Models}

\section{A.1 Sticky-Price Model}

\section{The Representative Consumer}

The lifetime utility is: $U=E_{0} \sum_{t=0}^{\infty} \beta^{t}\left(\frac{1}{1-\frac{1}{\tau}}\left(\frac{C_{t}}{C_{t-1}^{\gamma}}\right)^{1-\frac{1}{\tau}}-v \frac{N_{t}^{1-\varphi}}{1+\varphi}\right)$

The variable $C_{t}$ stands for aggregate consumption, $N_{t}$ is the amount of labor offered by the representative consumer in the job market. The parameter $\tau$ is the relative risk aversion of the agent. The parameter $\gamma$ controls the degree of habit persistence in consumption. In addition, the parameters $v$ and $\varphi$ control labor supply. The parameter $\beta$, between zero and one, is the intertemporal discount factor.

The representative consumer maximizes $U$, subject to the following budget constraint:

$$
B_{t+1}-B_{t}=W_{t} N_{t}+i_{t} B_{t}+P_{t} C_{t}
$$


The variable $B_{t}$ stands for the nominal bond. The letters $W_{t}$ and $P_{t}$ represent nominal wages and prices. The letter $i_{t}$ is the nominal interest rate on bonds. The consumer maximizes $U$ subject to the budget constraint.

\section{The Representative Firm}

There is a continuum of firms, indexed by $\mathrm{j}$, which operate a linear technology, according to the linear production function $Y_{t}(j)=A_{t} N_{t}(j)$, in which $A_{t}$ stands for an aggregate technology shock. They produce differentiated goods, which compose a final aggregate consumption good, represented by

$$
Y_{t}=\left(\int_{0}^{1} Y_{t}^{\frac{\varepsilon-1}{\varepsilon}}(j) d j\right)^{\frac{\varepsilon}{\varepsilon-1}},
$$

where $\varepsilon$ is the elasticity of substitution.

The environment is that of monopolistic competition, therefore the firm can choose its price. Following the Calvo (1983) scheme of pricing, a particular firm may reset its price with a probability given by $1-\theta$ in any given time, independently of the time elapsed since the last price was set. Therefore, a fraction $1-\theta$ of the firms set prices, while another fraction of $\theta$ keep their previous prices, without any change.

Firms maximize the discounted profits, taking into account that they will not be able to change the prices, unless they receive a green light to do so with probability $1-\theta$.

Following Christiano et al. (2005), I introduce an indexation mechanism in which firms that do not set prices optimally at time $t$ will adjust their prices to lagged inflation, according to the equation $P_{t+i}=P_{t+i-1}(j)\left(\pi_{t+i-1}\right)^{\omega}$, where the parameter $\omega$ indicates the degree of price indexation. The variables $P_{t}$ and $\pi_{t}$ denotes the price level and inflation.

The optimal price set by firms allowed to change prices is $P_{t}^{*}$ and the aggregate price level evolves according to the expression:

$$
P_{t}=\left[\theta\left(P_{t-1}\left(\pi_{t-1}\right)^{\omega}\right)^{1-\varepsilon}+(1-\theta)\left(P_{t}^{*}\right)^{1-\varepsilon}\right]^{\frac{1}{1-\varepsilon}}
$$

The derivation of the supply side of the model is standard and advanced macroeconomics textbook describe it in details. For instance, Galí (2008) develops the algebra step-by-step. In the neighborhood of zero steady state inflation, the New Keynesian Phillips Curve characterizes inflation dynamics according to equation 2. The expression for the parameter $\kappa$ is $\kappa=\frac{(1-\beta \theta)(1-\theta)}{\theta}$. The parameter $\mathcal{K}$ is strictly decreasing in $\theta$, a measure of the degree of nominal price rigidity.

Monetary Policy is described by Taylor rules in equations 3 and 4

\section{A.2 Sticky-Information Model}

\section{The Representative Consumer}

The description of the representative household in the sticky-information model is the same description presented in the sticky-price model; and for the sake of brevity, I do not repeat the specifications for preferences and the budget constraint. 


\section{The Representative Firm}

I follow the description presented in Mankiw \& Reis (2002) Every firm sets prices every period $t$, but the information needed to update prices optimally flows slowly over time. In each period, a fraction $\lambda$ of the firms obtains new information about the economy, which they use to compute the updated path for optimal prices. The remaining firms set prices based on outdated information. The arrival of information is such that each firm has the same probability of being one of the firms that gather new information, regardless of how long it has been since its last informational update. In this context, the optimal price is $p_{t}^{*}=p_{t}+\alpha y_{t}$. The variables $p_{t}$ and $y_{t}$ are the price level and the output gap in logarithmic scale.

A firm that last updated its information set $\mathrm{j}$ periods ago sets price according to the following expression: $x_{t}^{j}=E_{t-j}\left(p_{t}^{*}\right)$. The aggregate price level is the average of prices of all firms deciding prices at the period $t$, which is:

$$
p_{t}=\lambda \sum_{j=0}^{\infty}(1-\lambda)^{j} x_{t}^{j}=\lambda \sum_{j=0}^{\infty}(1-\lambda)^{j} E_{t-j}\left(p_{t}+\alpha y_{t}\right)
$$

By taking out the first term and redefining the index in the sum, this equation becomes:

$$
p_{t}=\lambda\left(p_{t}+\alpha y_{t}\right)+\lambda \sum_{j=0}^{\infty}(1-\lambda)^{j+1} E_{t-1-j}\left(p_{t}+\alpha y_{t}\right)
$$

The previous period price is:

$$
p_{t-1}=\lambda \sum_{j=0}^{\infty}(1-\lambda)^{j} E_{t-1-j}\left(p_{t-1}+\alpha y_{t-1}\right)
$$

Subtracting (III) from (II), inflation $\pi_{t}$ evolves according to the equation:

$$
\begin{aligned}
\pi_{t} & =\lambda\left(p_{t}+\alpha y_{t}\right)+\lambda \sum_{j=0}^{\infty}(1-\lambda)^{j+1} E_{t-1-j}\left[\pi_{t}+\alpha\left(y_{t}-y_{t-1}\right)\right] \\
& +\lambda^{2} \sum_{j=0}^{\infty}(1-\lambda)^{j} E_{t-1-j}\left(p_{t}+\alpha y_{t}\right)
\end{aligned}
$$

By rearranging equation (II), I can show that

$$
p_{t}-\left(\frac{\alpha \lambda}{1-\lambda}\right) y_{t}=\lambda \sum_{j=0}^{\infty}(1-\lambda)^{j} E_{t-1-j}\left(p_{t}+\alpha y_{t}\right)
$$

I use equation (V) to substitute for the last term in equation (IV). After some algebra, the final expression is:

$$
\pi_{t}=\left(\frac{\lambda \alpha}{1-\lambda}\right) y_{t}+\lambda \sum_{j=0}^{\infty}(1-\lambda)^{j} E_{t-1-j}\left[\pi_{t}+\alpha\left(y_{t}-y_{t-1}\right)\right]
$$

The final expression is equation 5 in section 3 of the paper, without the exogenous cost-push shock.

Monetary Policy, as in the sticky-price model, is described by Taylor rules in equations 3 and 4 


\section{Appendix B Filtering Techniques and Simulations}

This appendix provides some references on the filtering methods used to compute the output gap and details on how I conducted simulations on the models I considered in this paper.

\section{B.1 Filtering Techniques}

To compute the output gap, I use two different filters. The first one is the traditional Hodrick-Prescott Filter, discussed in Kydland \& Prescott (1990), with smoothing parameters equals to 1600 (the standard specification for quarterly data). The second method I used to extract the output cyclical component is a band pass filter proposed by Christiano \& Fitzgerald (2003). This filter extracts the components related to the business cycles (frequencies associated with eight to thirty two quarters), eliminating very low and very high frequency movements in the data.

\section{B.2 Simulations}

To solve the models, I used the method proposed by Klein (2000), based on the Generalized Shur-QZ decomposition of the rational expectation system composed by the IS equation, the Taylor rule and the alternative Phillips curve specifications. I simulated de models performing 5000 runs. Each run has the numbers of observations that matches the empirical samples of quarterly data. Therefore, for each run, I have time series with length 64 for Brazil and 176 for the U.S. I discarded 500 runs prior to the computation of the statistics based on the simulations. For the case of the sticky information Phillips curve, following Coibion (2010), I truncated the infinite sum in equation 5 and considered 15 terms in the sum. 